\title{
Knowledge and attitudes of students of College of Medicine towards evidence-based medicine and barriers to its use in clinical practice in Erbil city, Iraq
}

Received: 6/8/2014

Accepted: 24/12/2014

\begin{tabular}{ccc}
\hline Ali Shakir Dauod * & Samir M. Othman * & Kameran H. Ismail * \\
\hline Abstract
\end{tabular}

Background and objective: Evidence-based medicine, by guiding medical care towards meaningful outcomes to patients, has a significant worldwide impact on medical care and education. It is important that medical students, whom are the future physicians, keep themselves updated with recent advancement in medical knowledge and health care. The aim of this cross-sectional study was to determine the attitude, knowledge and barriers among students towards evidence-based medicine and making them familiar with the concept and advantage of evidence based medicine.

Methods: A cross-sectional study was conducted on 163 sixth year students of the College of Medicine at Hawler Medical University during the period from October 2012 to May 2013. The response rate was $86.5 \%$. Knowledge towards evidence-based medicine, accessing and interpreting evidence and perceived barriers to practice evidence-based medicine among participants were the main outcome measures.

Results: Of 141 of participants that filled the questionnaire, only $69.5 \%$ had heard about evidence-based medicine. Around $82 \%$ stated that they had knew evidence-based medicine and only $23.5 \%$ had knew steps of evidence-based medicine. Around $65 \%$ of respondents welcomed the promotion of evidence-based medicine and $74.4 \%$ agreed with that finding from the current study in which it would be helpful in daily management of patients. Furthermore, $31.6 \%$ of students reported that standard textbook as a frequent source used for medical knowledge. Around $91 \%$ of students did not know the strongest evidence in the hierarchy of evidence and only small proportion of students reported that they understand the common epidemiological concepts that are used in evidence-based medicine.

Conclusion: Evidence-based medicine is relatively a new concept among students at the College of Medicine in Erbil. Although the students appeared interested in learning and implementing evidence-based medicine in clinical practice, they need more guidance and training to ensure the correct use of evidence-based medicine ideals.

Keywords: Evidence-based medicine, Knowledge, Barriers, Erbil-Iraq.

\section{Introduction}

Evidence-based medicine (EBM) is defined as the "conscientious, explicit, and judicious use of current best evidence". ${ }^{1,2}$ Later David Sackett et al, refined the definition of EBM as "Integrating the best research evidence with clinical expertise and patient values and circumstances to achieve the best possible patient management". ${ }^{1}$ By best research evidence we mean valid and relevant research, often from the basic sciences of medicine, however the patient-centered clinical research into the accuracy of diagnostic tests, the power of prognostic markers, the efficacy and safety of therapeutic, rehabilitative and preventive regimens should be taken in consideration. By clinical expertise we mean the ability to use our clinical skills and past experience to rapidly identify each patient's unique health state and diagnosis, their individual risks and benefits of potential interventions, their personal circumstances and expectations.

* Department of community medicine, college of medicine, Hawler Medical University, Erbil, Iraq. 
By patient values we mean the unique preferences, concerns and expectations of each patient which must be integrated into clinical decisions if they are to serve the patient. By patient circumstances we mean their individual clinical state and the clinical setting. ${ }^{3}$ The patient's concerns and values also need to be taken as an important of approach and management. ${ }^{1}$ To complete the practice of EBM, the following five steps are required:

Step 1: Converting the need for information about (prevention, diagnosis, prognosis, therapy, causation and...etc) into an answerable question.

Step 2: Tracking down the best evidence with which to answer that question.

Step 3: Critically appraising that evidence for its validity (closeness to the truth), impact (size of the effect) and applicability (usefulness in our clinical practice).

Step 4: Integrating the critical appraisal with our clinical expertise and with our patient's unique biology, values and circumstances.

Step 5: Evaluating our effectiveness and efficiency in implementing steps 1-4 and inquiring about ways to improve them for next time. ${ }^{3}$

EBM is a trial to improve the quality of the information on which decisions are based; unfortunately, there is a large information gap between research and clinical practice. In 1972, British epidemiologist Archie Cochrane highlighted the fact that most treatment-related decisions were based on unplanned selection of information from the vast and variable quality scientific literature, on skilled opinion, or, worse of all, on trial and error. ${ }^{1}$ Medical sciences are continuously growing. In order to ensure that their skills and knowledge go with the needs of their patients, it is important that physicians and medical students, whom are the future physicians, keep themselves updated with recent advancement in medical knowledge and health care. A previous study showed that the longer since graduation from medical school the lower the accuracy in knowledge and quality of medical care given to patients. ${ }^{4}$ Knowledge and skills of EBM can be taught by many methods; however, little research has been conducted to reveal how best we can teach the knowledge, attitudes and skills of practicing and teaching EBM to medical students. There are three modes of teaching EBM; role-modeling practice of EBM, teaching clinical medicine with evidence and teaching specific EBM skills. Moreover EBM can be taught by seminars and workshops. ${ }^{3}$ The utilization of research, which is the backbone of EBM, is still in its infancy in developing countries. ${ }^{2}$ Previous studies proved that there was an overall positive attitude, knowledge and skills towards EBM. On the other hand, other studies stated that the concept of EBM was still unfamiliar to most of the medical students and residents, and there is in need of the incorporating formal teaching of EBM at all levels of medical education. ${ }^{2}$ A number of other reports discussed responses to EBM across various disciplines in different countries. ${ }^{4}$ No information is available regarding EBM knowledge and attitudes among students at Hawler Medical College in Iraq, so the aims of this study was to assess the attitude, knowledge and barriers among students and making them familiar with the concept and advantage of EBM.

\section{Methods}

\section{Study Sample:}

This cross-sectional study was conducted on the sixth stage medical students in the College of Medicine, Hawler Medical University in Erbil governorate, capital of Iraqi Kurdistan region. During the academic year 2012-2013, 163 sixth stage medical students were distributed into four groups; the first three groups consisted of 41 students and the last group consisted of 40 students. The four groups joined the mandatory two weeks course of primary health care at Brayatii Center, the first family medicine health center which was founded in 2010 . 
Questionnaire: All students in the four groups during the period from October 2012 to May 2013 were asked to complete a self-administrated questionnaire. The response rate was $86.5 \%$. The questionnaire was basically prepared and developed on the basis of a previous survey ${ }^{5}$ to assess students' knowledge and attitude towards EBM. The study preserved the anonymity and confidentiality of participants. The questionnaire consisted of six sections (from $A$ to $F$ ). Section $A$ was about personal characteristics including age and sex, section $B$ concentrated on attitudes toward EBM consisting of many questions. The main purpose of the questions was to know their familiarity with EBM, its concepts and principles or steps and their agreement about national program for teaching EBM and their agreement on EBM integration to the curriculum. Section $C$ included several questions which focused on accessing and interpreting the evidence by knowing their participation in any formal training in research strategy and their preferable relation to electronic web base as PubMed, Medline, Cochrane or other bibliographic databases and their most frequent sources of medical knowledge as standard textbook. Section D was about their knowledge on terms like relative risk, absolute risk, odds ratio, and other common epidemiological terms that are used in articles and studies of EBM. Section $E$ contained the most important barriers that anticipate the application of EBM in practice according to student's insight, like lack of personal time, lack of knowledge, lack of training, absence of library in the locally, limited resource and facilities, lack of appropriate information, lack of critical appraisal skill, absence of an effective computer system, lack of emphasis on EBM in undergraduate curricula and EBM is difficult to understand. In the latter part of the study and after students finished the first five parts of the questionnaire, there was a short seminar to discuss the importance, steps, and concepts of EBM and how to apply it to any medical information. Then section $F$ part of the questionnaire was distributed, which contained an example of the use of statin drug by a randomized clinical trial and all participants were asked to categorize the type of study as grading of evidence $A, B$ or $C$ depending upon EBM. Grading of evidence was simply defined as: level $A$ : evidence from a systematic review of all relevant randomized controlled trials, level B: evidence obtained from at least one well-designed Randomized Controlled Trial, and level $\mathrm{C}$ : evidence obtained from well-designed controlled trials without randomization.

Statistical analysis: The statistical package for the social sciences (version 18) was used for data analysis.

\section{Results \\ Students' characteristics}

Of 163 sixth year medical students at Hawler Medical University, 141(86.5\%) completed the questionnaire. Ninety eight $(69.5 \%)$ participants that had heard about EBM were enrolled in the subsequent analysis. The socio-demographic characteristics of the 141 students, $74(52.5 \%)$ males and $67(47.5 \%)$ females are described in Table 1.

Table 1: The socio-demographic characteristics of the 141 medical students at Hawler Medical University

\begin{tabular}{lll}
\hline Variable & $\mathbf{n}$ & $\%$ \\
\hline Gender & & \\
Male & 74 & 52.5 \\
Female & 67 & 47.5 \\
Age (year) & & \\
$\leq 25$ & 132 & 93.6 \\
$>25$ & 9 & 6.4 \\
Total & $\mathbf{1 4 1}$ & $\mathbf{1 0 0}$ \\
\hline
\end{tabular}


Students' EBM experience

About two thirds of respondents (69.5\%) had heard about EBM, nearly (81.6\%) stated that they had knew EBM and only about $(23.5 \%)$ knew the steps of EBM. Around $21 \%$ had ever received formal training in search strategy, $14.3 \%$ had received formal training in critical appraisal and only $22.4 \%$ had attended courses related to EBM. Around $24 \%$ of respondents stated that they are aware of Medline or Cochrane and only $29.6 \%$ reported that they are aware of guidelines or protocols.

\section{Attitude of students toward EBM}

About $65 \%$ welcomed the promotion of EBM and $74.4 \%$ agreed on that research finding are helpful in daily management of patients. About $77.6 \%$ stated that practicing of EBM would improves patient care, $74.5 \%$ stated that EBM reduces health care costs, and $58.2 \%$ stated that practicing EBM does not replace clinical experience. On the other hand, $48.0 \%$ stated that EBM is good concept but it has a limited value in general practice and $49.0 \%$ reported that EBM is not applicable to their culture. About $73.5 \%$ of students reported that EBM national program for teaching should be performed and $69.4 \%$ reported that EBM teaching courses should be part of curriculum for medical students. Table 2 shows the attitudes of students towards EBM.

Table 3: Students' level of understanding of the common epidemiological concepts that are used in EBM ( $\mathrm{N}=98)$

\begin{tabular}{lllll}
\hline Epidemiological concept & $\begin{array}{l}\text { It would not be } \\
\text { helpful to me } \\
\text { to understand } \\
\%\end{array}$ & $\begin{array}{l}\text { Do not } \\
\text { understand but } \\
\text { would like to } \\
\%\end{array}$ & $\begin{array}{l}\text { Some } \\
\text { understanding }\end{array}$ & $\begin{array}{l}\text { Understand } \\
\text { and could } \\
\text { explain to } \\
\text { others } \\
\%\end{array}$ \\
\hline Relative risk & 18.4 & 9.2 & 45.9 & 26.5 \\
Absolute risk & 17.3 & 22.4 & 27.6 & 32.7 \\
Odds ratio & 41.8 & 21.4 & 29.6 & 7.1 \\
Systematic review & 20.4 & 22.4 & 33.7 & 23.5 \\
Meta-analysis & 42.9 & 33.7 & 17.3 & 6.1 \\
Number needed to treat & 40.8 & 27.6 & 19.4 & 12.2 \\
Confidence interval & 37.8 & 26.5 & 25.5 & 10.2 \\
Publication bias & 39.8 & 25.5 & 21.4 & 13.3 \\
Prevalence of disease & 18.4 & 7.1 & 31.6 & 42.9 \\
Incidence of disease & 15.3 & 8.2 & 28.6 & 48.0 \\
Cohort study & 27.6 & 25.5 & 25.5 & 21.4 \\
Cross sectional study & 19.4 & 19.4 & 39.8 & 21.4 \\
Case control study & 16.3 & 20.4 & 42.9 & 20.4 \\
Randomized clinical study & 21.4 & 12.2 & 49.0 & 17.3 \\
Sensitivity of a diagnostic test & 11.2 & 16.3 & 31.6 & 40.8 \\
Specificity of a diagnostic test & 18.4 & 8.2 & 25.5 & 48.0 \\
Heterogeneity & 36.7 & 19.4 & 17.3 & 26.5 \\
Clinical effectiveness & 26.5 & 23.5 & 28.6 & 21.4 \\
\hline \hline & & & & \\
\hline
\end{tabular}


Barriers to practicing EBM

Table 4 shows several perceived barriers to practicing the EBM that were reported by students. Lack of training, lack of emphasis on EBM in undergraduate curriculum, and lack of appropriate skills were the most commonly reported barriers and found to be $85.7 \%, 78.6 \%$ and $78.6 \%$, respectively. Grading of evidence and the usefulness of EBM short seminars

When students were asked about the statin study in order to evaluate the hierarchy of the evidence, the obtained results showed that $63.3 \%, 32.7 \%$ and $4.1 \%$ were within the grade of evidence $A, B$ and $C$, respectively. On the other hand, when they were asked about the feasibility of a short seminar on the concepts and steps of EBM, and randomized controlled trial example, $84.7 \%$ of students reported that it is very useful.

\section{Discussion}

About $65.3 \%$ of participants had positive attitude and welcomed the promotion of EBM, $77.6 \%$ stated that practicing of EBM would improves patient care, and reduces health care costs, and $48.0 \%$ stated that EBM is good concept but it has a limited value in general practice. However, the present study revealed that only small proportion of students reported that they understand and able to explain the common epidemiological concepts that are used in EBM, results which are similar to another studies. ${ }^{6,7}$ The results of this study confirm the idea that practice of EBM is still in its early stage in our college. Even those who had some idea about EBM, they consider EBM is equivalent to experts' opinions, eliciting clinical findings and ordering laboratory investigations. The most commonly mentioned barrier to the practice of EBM was lack of training, lack of emphasis on EBM in undergraduate curricula and lack of critical appraisal skills. This could be explained by the fact that EBM is a relatively new concept and consequently training courses in EBM are rare. One way to increase the time available to practice EBM would be to change the emphasis of postgraduate education from lecturing to training in the access and interpretation of evidence and in the use of these skills in practice. ${ }^{8,9}$ This would require a major initiative at all three levels of education, i.e., undergraduate, postgraduate and CME. Various strategies can be adopted to bring the awareness and improve the skills regarding practice of EBM. These need to be targeted a all levels of medical education.

Table 4: Perceived barriers to practicing EBM $(\mathrm{N}=98)$.

\begin{tabular}{lll}
\hline Barrier & $\mathbf{n}$ & $\mathbf{\%}$ \\
\hline Lack of personal time & 68 & 69.4 \\
Lack of knowledge & 71 & 72.4 \\
Lack of training & 84 & 85.7 \\
Absence of library in the locally & 54 & 55.1 \\
Limited resources and facilities & 64 & 65.3 \\
Lack of appropriate information & 65 & 66.3 \\
Lack of critical appraisal skills & 77 & 78.6 \\
The absence of an effective computer system & 41 & 41.8 \\
Lack of emphasis on EBM in undergraduate curricula & 77 & 78.6 \\
EBM is difficult to understand & 58 & 59.2 \\
\hline \hline
\end{tabular}


http://dx.doi.org/10.15218/zjms.2015.0040

EBM workshop is an important tool. This can quickly build the required knowledge, skills and attitudes pertaining to EBM. Such workshops have worked in Pakistan for both under graduates and practicing students. ${ }^{10}$ The term EBM entered the lexicon in 1992. Since then, it has become the latest focus in the search for improved health care. The utilization of research, which represents the backbone of EBM, is still in its early stage in developing countries. A study conducted in Pakistan found that only $20 \%$ of residents read medical journals on the monthly basis, only $12 \%$ had ever wrote for medical journal publication, and $12 \%$ had never read a medical journal. ${ }^{11}$ In the current study; insufficient time was another barrier; this might be attributed to extremely heavy workloads. The obstacle of insufficient time was echoed in many other studies. ${ }^{12,13}$ Lack of knowledge was another barrier by the two-thirds of the participants of this study which is in agreement with findings of other studies, ${ }^{14}$ while others found the main barrier to be limited access. ${ }^{9,15,16}$ There is variation in how EBM is taught and there are studies that have focused on different types of EBM courses for students such as workshops, morning reports, rounds, seminars, short courses and journal clubs. ${ }^{17-19}$. Prior to seminar about EBM, our student's knowledge and how to use evidence in clinical practice was poor, and $90.8 \%$ of students did not know the strongest evidence in the EBM concept in the hierarchy of evidence. However, there was improvement in their practicing evidence-based after the seminar, were $64 \%$ of them solved the clinical based example correctly, and $84.7 \%$ of them reported that the seminar was very useful. This finding was in agreement with the finding of others. ${ }^{6,7,20}$ This study has a number of limitations. Students of groups 2 , 3 and 4 will hear about the research of EBM from their colleagues of group 1, which will inflate the level of knowledge. Secondly, some of the closed ended questions in the questionnaire are leading questions. Finally, there are a considerable proportion of students that mentioned they know many epidemiological terms, but it is difficult to confirm that they really know them.

\section{Conclusion}

EBM is a relatively new concept and its implementation at the College of Medicine in Erbil is in its infancy. Using the evidence and incorporating patients' values and preferences are extremely significant for this paradigm of medical practice. EBM is an essential competency for modern day medical education which has positive impact on health care outcomes. Integration of EBM into a medical school curriculum results in an improvement of attitude about EBM and also an improvement in self-reported skills for using EBM. Further study is needed to assess the long-term effects of teaching EBM on future medical practice.

\section{Conflicts of interest}

The authors report no conflicts of interest.

\section{References}

1. Glasziou P, Del Mar C, Salisbury J. Evidence based medicine workbook. Finding and applying the best research evidence to improve patient care. $2^{\text {nd }}$ ed. London: BMJ books; 2007.

2. Irshad A, Ramzan M, Iqbal M. Assessment of knowledge about evidence based medicine in medical students and doctors in a Pakistani health care setting. Pakistan J Ayub Med Coll Abbottabad 2010; 22(2):126-9.

3. Straus SE, Richardson WS, Glasziou P, Haynes RB. Evidence-based medicine how to practice and teach EBM. $3^{\text {rd }}$ ed. London: Elsevier Churchill Livingstone; 2005.

4. Risahmawati, Emura S, Nishi T, Widodo DW, Ismail I, Sugioka T, Koizumi S. A comparative assessment of attitudes, knowledge and selfperceived barrier to the practice of evidence based medicine in Japan and Indonesia. J Med Med Sci 2012; 3(1):16-29.

5. McColl A, Smith H, White P, Field J. General partitions of the route to evidence based medicine: questionnaire survey. BMJ 1998; 316:361-5.

6. Khader YS, Batayha W, Al-Omari M. The effect of evidence-based medicine (EBM) training seminars on the knowledge and attitudes of medical students towards EBM. J Eval Clin Pract 2011; 17(4):640-3. 
7. Hassanien MA. Introduction to Evidence-Based Medicine: a student-selected component at the Faculty of Medicine, King Abdulaziz University. J Adv Med Educ Pract 2011; 2:215-9.

8. Dawes MG. On the need for evidence-based general and family practice. EBM 1996; 1:68-9.

9. Al-Omari FK, Al-Asmary SM. Attitude, awareness and practice of evidence based medicine among consultant physicians in Western region of Saudi Arabia. Saudi Med J 2006; 27:1887-93.

10. Iqbal M, Zaidi Z. The 'ripple effect' of introducing Evidence based medicine into a curriculum. Med Educ J 2009; 43:475.

11. Evidence-based medicine working group Evidence-based medicine. A new approach to teaching the practice of medicine. JAMA 1992; 268 (17):2420-5.

12. Aslam F, Qayyum MA, Mahmud H, Qasim R, Haque IU. Attitudes and practices of post graduate medical trainees towards research -a snapshot from Faisalabad. J Pak Med Assoc 2004; 54: 534-6.

13. Al-Ansary LA, Khoja TA. The place of evidence-based medicine among primary health care physicians in Riyadh region, Saudi Arabia. J Fam Pract 2002; 19(5):537-42.

14. Amin FA, Fedorowicz Z, Montgomery AJ. A study of knowledge and attitudes toward the use of evidence-based medicine among primary health care physicians in Bahrain. Saudi Med J 2006; 27 (9):1394-6.

15. Al-Almaie SM, AL-Baghli N. Barriers facing physicians practicing evidence based medicine in Saudi Arabia. J Contin Educ Health Prof 2004; 24 (3):163-70.

16. Scott I, Heyworth R, Fairweather P. The use of evidence-based medicine in the practice of consultant physicians. Results of a questionnaire survey. Aust NZ J 2000; 30(3):319-26.

17. Reilly B, Lemon M. Evidence-based morning report: a popular new format in a large teaching hospital. Am J Med 1997; 103:419-26.

18. Bazarian JJ, Davis CO, Spillane LL, Blumstein H, Schneider SM. Teaching emergency medicine residents evidence-based critical appraisal skills: a controlled trial. Ann Emerg Med 1999; 34:148-54.

19. Green ML, Ellis PJ. Impact of an evidence-based medicine curriculum based on adult learning theory. J Gen Intern Med 1997; 12:742-750.

20. Okoromah CA, Adenuga AO, Lesi FE. Evidence-based medicine curriculum: impact on medical students. Med Educ 2006; 40:465-466. 